\title{
Luna Sensation 500 SC - new fungicide for control of black currant fungal diseases
}

\author{
Luna Sensation 500 SC - nowy fungicyd \\ do zwalczania chorób porzeczki czarnej
}

\author{
Agata Broniarek-Niemiec*
}

\begin{abstract}
Summary
American gooseberry mildew (Podosphaera mors-uvae), leaf spot (Drepanopeziza ribis) and white pine blister rust (Cronartium ribicola) are the most severe fungal diseases of black currant (Ribes nigrum). On commercial plantations control of these diseases is based mainly on the chemical method. However, the assortment of currently registered fungicides is limited to three products. The experiments, performed in 2010-2011 with new fungicide Luna Sensation 500 SC containing fluopyram and trifloxystrobin, showed its high effectiveness in control of black currant diseases. This fungicide applied at the doses of 0.6 and $0.8 \mathrm{l} /$ ha very effectively controlled American gooseberry mildew (over 96\%), leaf spot (over $88 \%$ ) and white pine blister rust (over 82\%). The effectiveness of Luna Sensation 500 SC was similar or higher than commonly used fungicides such as Score 250 EC and Signum 33 WG, thus it can be a suitable candidate recommended for efficient control of black currant fungal diseases, especially for anti resistant strategy.
\end{abstract}

Key words: American gooseberry mildew; leaf spot; white pine blister rust; chemical control; fluopyram; trifloxystrobin

\section{Streszczenie}

Amerykański mączniak agrestu (Podosphaera mors-uvae), antraknoza liści poprzeczki (Drepanopeziza ribis) oraz rdza wejmutkowoporzeczkowa (Cronartium ribicola) są najgroźniejszymi chorobami porzeczki czarnej (Ribes nigrum) powodowanymi przez grzyby. Na plantacjach towarowych zwalczanie tych chorób opiera się głównie na wykorzystaniu metody chemicznej, a asortyment zarejestrowanych środków jest ograniczony do trzech fungicydów. W latach 2010-2011 oceniano skuteczność nowego fungicydu Luna Sensation 500 SC, zawierającego fluopyram i trifloksystrobinę. Skuteczność testowanego fungicydu w zwalczaniu chorób porzeczki czarnej we wszystkich doświadczeniach była bardzo wysoka. Fungicyd Luna Sensation 500 SC stosowany zarówno w dawce 0,6, jak i 0,8 I/ha zwalczał amerykańskiego mączniaka agrestu w ponad $96 \%$, antraknozę liści porzeczki w ponad $88 \%$, a rdzę wejmutkowoporzeczkową w ponad $82 \%$. Skuteczność fungicydu Luna Sensation 500 SC była podobna do powszechnie stosowanych fungicydów Score 250 EC i Signum 33 WG lub wyższa. Fungicyd Luna Sensation 500 SC może być cennym rozszerzeniem środków polecanych do zwalczania chorób grzybowych na plantacjach porzeczki czarnej, zwłaszcza w ramach strategii antyodpornościowej.

Słowa kluczowe: amerykański mączniak agrestu; antraknoza liści poprzeczki; rdza wejmutkowo-porzeczkowa; ochrona chemiczna; fluopyram; trifloksystrobina

Instytut Ogrodnictwa

Pracownia Fitopatologii Sadowniczej

Pomologiczna 18, 96-100 Skierniewice

*corresponding author: agata.broniarek@inhort.pl 


\section{Wstęp / Introduction}

Polska od wielu lat jest liderem w produkcji owoców porzeczki czarnej. W ostatnich dziesięciu latach z powierzchni 27-37 tys. ha, przeciętne roczne zbiory kształtowały się na poziomie 100-145 tys. ton (Nosecka i Świetlik 2011; Nosecka 2014). Obecnie na towarowych plantacjach dominują nowe odmiany, pochodzące z polskiej hodowli, takie jak: Tisel, Tiben, Ruben, Ores, Gofert i Tines, zajmujące około $60 \%$ całkowitej powierzchni uprawy porzeczki czarnej. Obniża się areał odmian Ben Lomond, Titania czy Ojebyn (Pluta i Baryła 2014). Wszystkie uprawiane odmiany porzeczki czarnej są w różnym stopniu podatne na antraknozę liści porzeczki [Drepanopeziza ribis (Kleb.)], amerykańskiego mączniaka agrestu [Podosphaera mors-uvae (Schw.)] i rdzę wejmutkowo-porzeczkową (Cronartium ribicola J.C. Fischer). Ochrona porzeczki przed tymi chorobami oparta jest przede wszystkim na wielokrotnym opryskiwaniu roślin fungicydami w okresie wegetacji. Obecnie asortyment preparatów polecanych do ich zwalczania jest ograniczony do trzech fungicydów: Score 250 EC (difenokonazol), Signum 33 WG (piraklostrobina + boskalid), Zato $50 \mathrm{WG}$ (trifloksystrobina) (Broniarek-Niemiec i Bielenin 2010; Broniarek-Niemiec 2013; Broniarek-Niemiec i wsp. 2014). Konieczne jest poszukiwanie nowych środków, charakteryzujących się wysoką skutecznością i możliwością zastosowania w ramach strategii antyodpornościowej. Jednym $\mathrm{z}$ takich preparatów może być Luna Sensation 500 SC. Substancjami czynnymi tego fungicydu są fluopyram i trifloksystrobina. Fluopyram jest jedną $\mathrm{z}$ najnowszych substancji rozwijającej się grupy SDHI (inhibitory enzymu dehydrogenazy kwasu bursztynowego), której działanie polega na hamowaniu oddychania mitochondrialnego grzybów w kompleksie II łańcucha oddechowego (Avenot i Michailides 2010). Dzięki wielokierunkowemu działaniu na i w roślinie (powierzchniowo, translaminarnie i systemicznie) fluopyram może być skuteczny przeciwko różnym chorobom powodowanym przez grzyby (Proffer i wsp. 2013). Trifloksystrobina jest szeroko stosowana do ochrony roślin sadowniczych, w tym także porzeczki i agrestu (Broniarek-Niemiec i Bielenin 2003, 2008).

Celem pracy była ocena skuteczności działania fungicydu Luna Sensation 500 SC w zwalczaniu amerykańskiego mączniaka agrestu, antraknozy liści porzeczki i rdzy wejmutkowo-porzeczkowej na plantacjach porzeczki czarnej.

\section{Materiały i metody / Materials and methods}

Oceniano skuteczność fungicydu Luna Sensation $500 \mathrm{SC}$ zawierającego w 1 litrze środka $250 \mathrm{~g}$ fluopyramu i 250 g trifloksystrobiny. Doświadczenia polowe przeprowadzono w latach 2010 i 2011, na 2 plantacjach porzeczki czarnej odmiany Ben Lomond, zlokalizowanych w centralnej Polsce: w Gągolinie Północnym (plantacja A) i w Głownie (plantacja B). Doświadczenia założono w układzie losowanych poletek, w 4 powtórzeniach po $10 \mathrm{krze}-$ wów na poletku. W sezonie 2010 wykonano 5 zabiegów: pierwszy bezpośrednio po kwitnieniu (faza $67 \mathrm{BBCH}$ ), kolejne przeciętnie co 11-13 dni. W sezonie 2011, ze względu na mniej sprzyjające rozwojowi chorób warunki pogodowe, wykonano 4 zabiegi: pierwszy około 2 tygodnie po kwitnieniu (faza $72 \mathrm{BBCH}$ ), kolejne co 12-14 dni. Dla porównania zastosowano fungicydy standardowe Score 250 WC i Signum 33 WG.

Biologiczną skuteczność badanych preparatów w zwalczaniu amerykańskiego mączniaka agrestu, antraknozy liści porzeczki i rdzy wejmutkowo-porzeczkowej oceniano oddzielnie dla każdej choroby na podstawie liczby porażonych pędów lub liści. Obserwacje nasilenia amerykańskiego mączniaka agrestu i antraknozy liści porzeczki przeprowadzono dwukrotnie w sezonie (przed i po zbiorze owoców). Ocenę skuteczności preparatów przeciwko rdzy wejmutkowo-porzeczkowej przeprowadzono po zbiorze owoców, kiedy objawy choroby występują w największym nasileniu. Każdorazowo oceniano 100 losowo wybranych pędów (w przypadku mączniaka) lub liści (w przypadku antraknozy i rdzy), w 4 powtórzeniach. Skuteczność badanych preparatów w zwalczaniu wyżej wymienionych chorób $\mathrm{w}$ stosunku do kombinacji kontrolnej obliczono według wzoru:

Skuteczność $=100 \%-(\mathrm{A} / \mathrm{B}) \times 100 \%$

$\mathrm{A}$ - procent porażonych liści lub pędów w kombinacji opryskiwanej,

$\mathrm{B}$ - procent porażonych liści lub pędów w kombinacji kontrolnej.

Wyniki opracowano statystycznie metodą analizy wariancji, którą dla danych wyrażonych w procentach przeprowadzono na wartościach przekształconych według funkcji Blissa. Różnice między średnimi oceniano przy użyciu testu Newmana-Keulsa przy poziomie istotności $5 \%$.

\section{Wyniki i dyskusja / Results and discussion}

Przeprowadzone badania wykazały, że fungicyd Luna Sensation 500 SC bardzo skutecznie chronił pędy i liście porzeczki czarnej przed amerykańskim mączniakiem agrestu. W obu latach badań w warunkach dużego nasilenia choroby (ponad $88 \%$ porażonych pędów na poletkach kontrolnych), skuteczność preparatu zarówno w dawce 0,6, jak i 0,8 1/ha wynosiła ponad $96 \%$. Skuteczność fungicydów standardowych Score 250 EC i Signum 33 WG w obu latach badań, na obydwu plantacjach była także wysoka i wynosiła od 84,8 do 99,4\%. Mimo to, była ona najczęściej niższa od fungicydu Luna Sensation 500 SC. Jedynie w 2010 r., podczas I oceny na plantacji B i podczas II oceny na plantacji A, skuteczność Signum 33 WG była podobna do fungicydu Luna Sensation 500 SC. Ponadto w 2011 r., w czasie I oceny na plantacji A skuteczność zarówno Signum 33 WG, jak i Score 250 EC była zbliżona do fungicydu Luna Sensation $500 \mathrm{SC}$ (tab. 1). Wysoką skuteczność fungicydu Luna Sensation 500 SC w zwalczaniu amerykańskiego mączniaka agrestu warunkują jego substancje czynne. Wcześniejsze badania wykazały, że trifloksystrobina była wysoce skuteczna w zwalczaniu mączniaków prawdziwych na różnych roślinach sadowniczych, w tym także na porzeczce i agreście 
Tabela 1. Skuteczność fungicydu Luna Sensation 500 SC w zwalczaniu amerykańskiego mączniaka agrestu (Podosphaera mors-uvae) na porzeczce czarnej

Table 1. The effectiveness of fungicide Luna Sensation $500 \mathrm{SC}$ in control of American gooseberry mildew (Podosphaera mors-uvae) on black currant

\begin{tabular}{|c|c|c|c|c|c|c|c|c|c|}
\hline \multirow{3}{*}{$\begin{array}{l}\text { Fungicyd } \\
\text { Fungicide }\end{array}$} & \multirow{3}{*}{$\begin{array}{l}\text { Dawka } \\
\text { na } 1 \text { ha } \\
\text { Dose } \\
\text { per } 1 \text { ha }\end{array}$} & \multicolumn{4}{|c|}{$\begin{array}{c}\text { I ocena } \\
\text { 1st assessment }\end{array}$} & \multicolumn{4}{|c|}{$\begin{array}{c}\text { II ocena } \\
\text { 2nd assessment }\end{array}$} \\
\hline & & \multicolumn{2}{|c|}{$\begin{array}{l}\text { procent porażonych pędów } \\
\text { per cent of infected shoots }\end{array}$} & \multicolumn{2}{|c|}{$\begin{array}{c}\text { skuteczność } \\
\text { effectiveness } \\
{[\%]}\end{array}$} & \multicolumn{2}{|c|}{$\begin{array}{l}\text { procent porażonych pędów } \\
\text { per cent of infected shoots }\end{array}$} & \multicolumn{2}{|c|}{$\begin{array}{c}\text { skuteczność } \\
\text { effectiveness } \\
{[\%]}\end{array}$} \\
\hline & & 2010 & 2011 & 2010 & 2011 & 2010 & 2011 & 2010 & 2011 \\
\hline \multicolumn{10}{|c|}{ Plantacja w Gągolinie Północnym - Plantation in Gągolin Północny } \\
\hline Kontrola - Check & & $92,5 \mathrm{~d}$ & $90,5 \mathrm{~b}$ & & & $95,1 \mathrm{c}$ & $90,5 \mathrm{c}$ & & \\
\hline Luna Sensation $500 \mathrm{SC}$ & 0,61 & $0,0 \mathrm{a}$ & $1,5 \mathrm{a}$ & 100,0 & 98,3 & $0,3 \mathrm{a}$ & $3,3 \mathrm{ab}$ & 99,7 & 96,4 \\
\hline Luna Sensation $500 \mathrm{SC}$ & 0,81 & $0,0 \mathrm{a}$ & $1,0 \mathrm{a}$ & 100,0 & 98,9 & $0,1 \mathrm{a}$ & $1,5 \mathrm{a}$ & 99,9 & 98,3 \\
\hline Score $250 \mathrm{EC}$ & 0,21 & $9,2 \mathrm{c}$ & $3,8 \mathrm{a}$ & 90,1 & 95,8 & $11,0 \mathrm{~b}$ & $5,0 \mathrm{~b}$ & 88,4 & 94,5 \\
\hline Signum $33 \mathrm{WG}$ & $1,8 \mathrm{~kg}$ & $0,6 \mathrm{~b}$ & $3,8 \mathrm{a}$ & 99,4 & 95,8 & $1,7 \mathrm{a}$ & $5,0 \mathrm{~b}$ & 98,2 & 94,5 \\
\hline \multicolumn{10}{|c|}{ Plantacja w Głownie - Plantation in Głowno } \\
\hline Kontrola-Check & & $88,9 \mathrm{c}$ & $99,0 \mathrm{c}$ & & & $75,5 \mathrm{c}$ & $89,3 \mathrm{~d}$ & & \\
\hline Luna Sensation $500 \mathrm{SC}$ & 0,61 & $1,1 \mathrm{a}$ & $2,3 \mathrm{a}$ & 98,8 & 97,7 & $2,5 \mathrm{a}$ & $2,0 \mathrm{a}$ & 96,7 & 97,8 \\
\hline Luna Sensation $500 \mathrm{SC}$ & 0,81 & $0,4 \mathrm{a}$ & $1,3 \mathrm{a}$ & 99,6 & 98,7 & $0,0 \mathrm{a}$ & $1,0 \mathrm{a}$ & 100,0 & 98,9 \\
\hline Score 250 EC & 0,21 & $7,7 \mathrm{~b}$ & $15,0 \mathrm{~b}$ & 91,3 & 84,8 & $10,3 \mathrm{~b}$ & $10,2 \mathrm{c}$ & 86,5 & 88,6 \\
\hline Signum $33 \mathrm{WG}$ & $1,8 \mathrm{~kg}$ & $2,1 \mathrm{a}$ & $11,5 \mathrm{~b}$ & 97,6 & 88,4 & $10,5 \mathrm{~b}$ & $4,9 \mathrm{~b}$ & 86,1 & 94,5 \\
\hline
\end{tabular}

Wartości w kolumnach i w poszczególnych plantacjach oznaczone tą samą literą nie różnią się istotnie przy p $=0,05$

Values in columns and in individual plantations followed by the same letter are not significantly different at $p=0.05$

(Broniarek-Niemiec i Bielenin 2003, 2008; BroniarekNiemiec 2004). W 2013 roku substancja ta (jako substancja czynna fungicydu Zato $50 \mathrm{WG}$ ) została zarejestrowana w Polsce do zwalczania chorób występujących na porzecze i agreście (Broniarek-Niemiec i wsp. 2014). Również badania innych autorów wskazują na dobre właściwości trifloksystrobiny oraz innych substancji $\mathrm{z}$ grupy strobiluryn $\mathrm{W}$ zwalczaniu mączniaków prawdziwych w uprawach sadowniczych. Jörg i wsp. (2000) wykazali wysoką skuteczność krezoksymu metylowego w ochronie agrestu, a Reuveni (2001) uzyskał dobre efekty ochrony nektaryn przed mączniakiem prawdziwym po zastosowaniu trifloksystrobiny i krezoksymu metylowego. Mieszaniny trifloksystrobiny i fluopyramu okazały się wysoce skuteczne w zwalczaniu mączniaków prawdziwych na wiśniach (Proffer i wsp. 2013) oraz na brzoskwiniach (Adaskaveg i wsp. 2009).

Fungicyd Luna Sensation 500 SC skutecznie zwalczał także antraknozę liści porzeczki i rdzę wejmutkowoporzeczkową. W doświadczeniach przeprowadzonych w latach 2010 i 2011 skuteczność tego fungicydu stosowanego w dawkach 0,6 i 0,8 1/ha w zwalczaniu antraknozy wynosiła ponad 88\%. W 2010 r. w warunkach wysokiego nasilenia antraknozy liści porzeczki (ponad 59\% porażonych liści na poletkach kontrolnych) była ona znacznie wyższa niż skuteczność fungicydów Score 250 EC i Signum 33 WG. Natomiast w 2011 r. przy średnim nasileniu choroby (19,3-56\% porażonych liści na poletkach kontrolnych), skuteczność fungicydu Luna Sensation 500 SC była taka sama, jak fungicydów standardowych. Rdza wejmutkowo-porzeczkowa, w zależności od roku badań i lokalizacji, wystąpiła w niskim lub średnim nasileniu. $\mathrm{Na}$ niechronionych krzewach (kontrolnych) w latach
2010-2011 obserwowano od 10 do 52\% porażonych liści. Przy takim nasileniu choroby w obu latach badań skuteczność fungicydu Luna Sensation 500 SC, zarówno w wyższej, jak i niższej dawce była bardzo wysoka i wynosiła ponad 97\%. Jedynie w 2011 roku skuteczność tego fungicydu w dawce $0,6 \mathrm{l} /$ ha wynosiła $82 \%$. Jednakże w obu latach badań skuteczność fungicydu była na podobnym poziomie, jak fungicydów standardowych Score 250 EC i Signum 33 WG lub wyższym.

Wcześniejsze badania własne również wykazały wysoką (ponad 80\%) skuteczność samej trifloksystrobiny w zwalczaniu antraknozy liści porzeczki i rdzy wejmutkowo-porzeczkowej. Przy czym skuteczność fungicydu opartego na tej substancji była podobna lub wyższa od fungicydów Score 250 EC i Signum 33 WG (BroniarekNiemiec 2004; Broniarek-Niemiec i wsp. 2014). Doskonałą skuteczność trifloksystrobiny w zwalczaniu antraknozy oraz zwyżkę plonu porzeczki czarnej wykazano także w badaniach angielskich (Locke i wsp. 2002). W dostępnej literaturze brak jest natomiast wyników badań dotyczących skuteczności fungicydu Luna Sensation 500 SC w zwalczaniu antraknozy liści porzeczki czy rdzy wejmutkowoporzeczkowej. Jedynie Proffer i wsp. (2013) podają, że mieszanina trifloksystrobiny i fluopyramu okazała się skuteczna w zwalczaniu drobnej plamistości liści drzew pestkowych na wiśniach. Na drzewach chronionych przez cały sezon tą mieszaniną porażonych było zaledwie 5,3\% liści, a defoliacja oceniana po zbiorze owoców objęła zaledwie 0,8\% pędów. Ponadto Avenot i Michailides (2010) oraz McKay i wsp. (2011) podają, że fungicydy z grupy SDHI, w tym także fluopyram, charakteryzują się szerokim spektrum zwalczanych chorób, a zwłaszcza tych powodowanych przez workowce i podstawczaki. Jedno- 
Tabela 2. Skuteczność fungicydu Luna Sensation $500 \mathrm{SC}$ w zwalczaniu antraknozy liści porzeczki (Drepanopeziza ribis)

Table 2. The effectiveness of fungicide Luna Sensation $500 \mathrm{SC}$ in control of leaf spot (Drepanopeziza ribis)

\begin{tabular}{|c|c|c|c|c|c|c|c|c|c|}
\hline \multirow{3}{*}{$\begin{array}{l}\text { Fungicyd } \\
\text { Fungicide }\end{array}$} & \multirow{3}{*}{$\begin{array}{c}\text { Dawka } \\
\text { na } 1 \text { ha } \\
\text { Dose } \\
\text { per } 1 \text { ha }\end{array}$} & \multicolumn{4}{|c|}{$\begin{array}{c}\text { I ocena } \\
\text { 1st assessment }\end{array}$} & \multicolumn{4}{|c|}{$\begin{array}{c}\text { II ocena } \\
\text { 2nd assessment }\end{array}$} \\
\hline & & \multicolumn{2}{|c|}{$\begin{array}{l}\text { procent porażonych liści } \\
\text { per cent of infected leaves }\end{array}$} & \multicolumn{2}{|c|}{$\begin{array}{c}\text { skuteczność } \\
\text { effectiveness } \\
{[\%]}\end{array}$} & \multicolumn{2}{|c|}{$\begin{array}{l}\text { procent porażonych liści } \\
\text { per cent of infected leaves }\end{array}$} & \multicolumn{2}{|c|}{$\begin{array}{c}\text { skuteczność } \\
\text { effectiveness } \\
{[\%]}\end{array}$} \\
\hline & & 2010 & 2011 & 2010 & 2011 & 2010 & 2011 & 2010 & 2011 \\
\hline \multicolumn{10}{|c|}{ Plantacja w Gągolinie Północnym - Plantation in Gągolin Północny } \\
\hline Kontrola - Check & & $59,9 \mathrm{~d}$ & $19,3 \mathrm{~b}$ & & & $70,6 \mathrm{~d}$ & $47,0 \mathrm{~b}$ & & \\
\hline Luna Sensation $500 \mathrm{SC}$ & 0,61 & $1,7 \mathrm{ab}$ & $2,3 \mathrm{a}$ & 97,2 & 88,1 & $2,1 \mathrm{a}$ & $5,3 \mathrm{a}$ & 97,0 & 88,7 \\
\hline Luna Sensation $500 \mathrm{SC}$ & 0,81 & $0,7 \mathrm{a}$ & $1,0 \mathrm{a}$ & 98,8 & 94,8 & $1,5 \mathrm{a}$ & $3,0 \mathrm{a}$ & 97,9 & 93,6 \\
\hline Score $250 \mathrm{EC}$ & 0,21 & $12,1 \mathrm{c}$ & $1,3 \mathrm{a}$ & 79,8 & 93,3 & $17,7 \mathrm{c}$ & $1,8 \mathrm{a}$ & 74,9 & 89,8 \\
\hline Signum $33 \mathrm{WG}$ & $1,8 \mathrm{~kg}$ & $3,8 \mathrm{~b}$ & $3,8 \mathrm{a}$ & 93,7 & 80,3 & $6,2 \mathrm{~b}$ & $6,0 \mathrm{a}$ & 91,2 & 87,2 \\
\hline \multicolumn{10}{|c|}{ Plantacja w Głownie - Plantation in Głowno } \\
\hline Kontrola - Check & & $68,3 \mathrm{~d}$ & $27,3 \mathrm{~b}$ & & & $75,0 \mathrm{~d}$ & $56,0 \mathrm{~b}$ & & \\
\hline Luna Sensation $500 \mathrm{SC}$ & 0,61 & $2,6 \mathrm{ab}$ & $2,3 \mathrm{a}$ & 96,2 & 91,6 & $4,0 \mathrm{ab}$ & $5,5 \mathrm{a}$ & 90,2 & 90,2 \\
\hline Luna Sensation $500 \mathrm{SC}$ & 0,81 & $1,2 \mathrm{a}$ & $0,8 \mathrm{a}$ & 98,2 & 97,1 & $2,2 \mathrm{a}$ & $1,3 \mathrm{a}$ & 97,7 & 97,7 \\
\hline Score $250 \mathrm{EC}$ & 0,21 & $14,7 \mathrm{c}$ & $1,8 \mathrm{a}$ & 78,5 & 93,4 & $15,1 \mathrm{c}$ & $5,3 \mathrm{a}$ & 90,5 & 90,5 \\
\hline Signum $33 \mathrm{WG}$ & $1,8 \mathrm{~kg}$ & $5,5 \mathrm{~b}$ & $3,8 \mathrm{a}$ & 91,9 & 86,1 & $7,4 \mathrm{~b}$ & $5,5 \mathrm{a}$ & 90,2 & 90,2 \\
\hline
\end{tabular}

Wartości w kolumnach i w poszczególnych plantacjach oznaczone tą samą literą nie różnią się istotnie przy p $=0,05$

Values in columns and in individual plantations followed by the same letter are not significantly different at $p=0.05$

Tabela 3. Skuteczność fungicydu Luna Sensation 500 SC w zwalczaniu rdzy wejmutkowo-porzeczkowej (Cronartium ribicola)

Table 3. The effectiveness of fungicide Luna Sensation $500 \mathrm{SC}$ in control of White Pine Blister Rust (Cronartium ribicola)

\begin{tabular}{|c|c|c|c|c|c|}
\hline \multirow{2}{*}{$\begin{array}{l}\text { Fungicyd } \\
\text { Fungicide }\end{array}$} & \multirow{2}{*}{$\begin{array}{l}\text { Dawka na } 1 \text { ha } \\
\text { Dose per } 1 \text { ha }\end{array}$} & \multicolumn{2}{|c|}{$\begin{array}{l}\text { Procent porażonych liści } \\
\text { Per cent of infected leaves }\end{array}$} & \multicolumn{2}{|c|}{$\begin{array}{c}\text { Skuteczność - Effectiveness } \\
{[\%]}\end{array}$} \\
\hline & & 2010 & 2011 & 2010 & 2011 \\
\hline \multicolumn{6}{|c|}{ Plantacja w Gągolinie Północnym - Plantation in Gągolin Północny } \\
\hline Kontrola - Check & & $20,6 \mathrm{~b}$ & $10,0 \mathrm{~b}$ & & \\
\hline Luna Sensation $500 \mathrm{SC}$ & 0,61 & $0,1 \mathrm{a}$ & $1,8 \mathrm{a}$ & 99,5 & 82,0 \\
\hline Luna Sensation $500 \mathrm{SC}$ & 0,81 & $0,0 \mathrm{a}$ & $0,3 \mathrm{a}$ & 100,0 & 97,0 \\
\hline Score $250 \mathrm{EC}$ & 0,21 & $0,0 \mathrm{a}$ & $0,8 \mathrm{a}$ & 100,0 & 92,0 \\
\hline Signum $33 \mathrm{WG}$ & $1,8 \mathrm{~kg}$ & $0,0 \mathrm{a}$ & $1,5 \mathrm{a}$ & 100,0 & 85,0 \\
\hline \multicolumn{6}{|c|}{ Plantacja w Głownie - Plantation in Głowno } \\
\hline Kontrola-Check & & $29,7 \mathrm{c}$ & $52,0 \mathrm{~b}$ & & \\
\hline Luna Sensation $500 \mathrm{SC}$ & 0,61 & $0,1 \mathrm{a}$ & $1,3 \mathrm{a}$ & 99,7 & 97,5 \\
\hline Luna Sensation $500 \mathrm{SC}$ & 0,81 & $0,1 \mathrm{a}$ & $0,5 \mathrm{a}$ & 99,7 & 99,0 \\
\hline Score $250 \mathrm{EC}$ & 0,21 & $4,7 \mathrm{~b}$ & $2,0 \mathrm{a}$ & 84,2 & 96,2 \\
\hline Signum $33 \mathrm{WG}$ & $1,8 \mathrm{~kg}$ & $2,4 \mathrm{~b}$ & $1,8 \mathrm{a}$ & 91,9 & 96,5 \\
\hline
\end{tabular}

Wartości w kolumnach i w poszczególnych plantacjach oznaczone tą samą literą nie różnią się istotnie przy $\mathrm{p}=0,05$

Values in columns and in individual plantations followed by the same letter are not significantly different at $\mathrm{p}=0.05$

cześnie podkreślają, że ze względu na specyficzny mechanizm działania fungicydy SDHI należą do grupy związków o wysokim ryzyku powstawania odporności. Jak dotychczas nie stwierdzono jednak krzyżowej odporności na te fungicydy u grzybów wykazujących odporność na fungicydy z grupy strobiluryn, benzimidazoli czy anilinopirymidyn. W programach przeciwdziałających powstawaniu odporności fungicydy SDHI powinny być stosowane 1 lub maksymalnie 2 razy $\mathrm{w}$ sezonie i zawsze przemiennie ze środkami o innym mechanizmie działania (Avenot i Michailides 2010; McKay i wsp. 2011; Proffer i wsp. 2013).

\section{Wnioski / Conclusions}

1. Fungicyd Luna Sensation 500 SC wykazał wysoką skuteczność w zwalczaniu amerykańskiego mączniaka agrestu, antraknozy liści porzeczki i rdzy wejmutkowoporzeczkowej. 
2. W celu przeciwdziałania powstawaniu odporności, Luna Sensation $500 \mathrm{SC}$ w ochronie porzeczki przed chorobami powinna być stosowana 1 lub maksymalnie
2 razy $w$ sezonie i zawsze przemiennie $\mathrm{z}$ fungicydami o innym mechanizmie działania.

\section{Literatura / References}

Adaskaveg J.E., Forster H., Thompson D., Felts D., Enns J., Day K., Beede B., Holtz B. 2009. Epidemiology and Management of Preand Postharvest Diseases of Peach, Plum and Nectarine. California Tree Fruit Agreement 2009 Annual Research Report: $29-49$. http://ucanr.edu/repositoryfiles/CTFA2009_29.pdf-92548.pdf [Accessed: 13.10.2014].

Avenot H.F., Michailides T.J. 2010. Progress in understanding molecular mechanisms and evolution of resistance to succinate dehydrogenase inhibiting (SDHI) fungicides in phytopathogenic fungi. Crop Protection 29: 643-651.

Broniarek-Niemiec A. 2004. Efektywność fungicydu Zato 50 WG w zwalczaniu chorób porzeczki czarnej. [Effectiveness of fungicide Zato 50 WG in control of blackcurrant diseases]. Progress in Plant Protection/Postępy w Ochronie Roślin 44 (2): 619-621.

Broniarek-Niemiec A. 2013. Nowe możliwości zwalczania amerykańskiego mączniaka agrestu (Sphaerotheca mors-uvae). [New possibilities for control of American powdery mildew (Sphaerotheca mors-uvae)]. Progress in Plant Protection/Postępy w Ochronie Roślin 53 (1): 123-126.

Broniarek-Niemiec A., Bielenin A. 2003. Skuteczność wybranych fungicydów w zwalczaniu amerykańskiego mączniaka agrestu i opadziny liści na plantacjach agrestu. [Efficacy of some fungicides in control of American gooseberry mildew and leaf spot on goosberry plantation]. Progress in Plant Protection/Postępy w Ochronie Roślin 43 (2): 545-547.

Broniarek-Niemiec A., Bielenin A. 2008. Effectiveness of trifloxystrobin and tolylfluanid mixture for control of blackcurrant diseases. Integrated Plant Protection in Soft Fruits. IOBC-WPRS Bulletin 39: 197-201.

Broniarek-Niemiec A., Bielenin A. 2010. Komentarz do programu ochrony porzeczki i agrestu przed chorobami. s. 50-54. Ogólnopolska Konferencja Nauka Praktyce. Uprawa Porzeczek i Agrestu. Skierniewice, 20.04.2010, 97 ss.

Broniarek-Niemiec A., Meszka B., Głos H. 2014. Ochrona truskawek, malin i porzeczek przed chorobami z uwzględnieniem zasad integrowanej ochrony roślin. 57. Ogólnopolska Konferencja Ochrony Roślin. Centrum Kongresowe Ossa koło Białej Rawskiej, 11-12.02.2014: 99-105.

Jörg E., Harzer U., Ollig W. 2000. Integrated approach for the control of American gooseberry mildew. IOBC-WPRS Bulletin 23 (11): $25-34$.

McKay A.H., Hagerty G.C., Follas G.B., Moore M.S., Christe M.S., Beresford R.M. 2011. Succinate dehydrogenase inhibitor (SDHI) fungicide resistance prevention strategy. New Zeland Plant Protection 64: 119-124.

Locke T., Bobbin P., Atwood J., Owen J. 2002. Effect of strobilurin fungicides on diseasae control and yield in blackcurrants. Acta Horticulturae 585, ISHS: 375-380.

Nosecka B. 2014. Zagospodarowanie porzeczek czarnych w Polsce. Materiały konferencyjne 4. Międzynarodowej Konferencji Porzeczkowej. Białowieża, 2-6.06.2014. http://www.internationalblackcurrantassociation.com/Marketing\%20\&\%20Market\%20Research.html [dostęp: 13.10.2014].

Nosecka B., Świetlik J. 2011. Wielkość zbiorów, potrzeby i opłacalność produkcji owoców truskawki, maliny i porzeczki czarnej ze szczególnym uwzględnieniem produkcji i potrzeb mrożonek owocowych. 31. Międzynarodowe Seminarium Sadownicze „Prognoza wielkości zbiorów, potrzeby i opłacalność produkcji owoców w kraju w najbliższych latach". Limanowa, 4-5.03.2011, 95 ss.

Pluta S., Baryła P. 2014. The role and future of Poland, as the largest producer of blackcurrants in the world. Materiały konferencyjne 4. Międzynarodowej Konferencji Porzeczkowej. Białowieża, 2-6.06.2014. http://www.internationalblackcurrantassociation.com/ Marketing\%20\&\%20Market\%20Research.html [dostęp: 13.10.2014].

Proffer T.J., Lizotte E., Rothwell N.L., Sundin G.W. 2013. Evaluation of dodine, fluopyram and penthiopyrad for management of leaf spot and powdery mildew of tart cherry, and fungicide sensivity sreening of Michigan populations of Blumeriella jaapii. Pest Management Science 69: 747-754.

Reuveni M. 2001. Improved control of powdery mildew (Sphaerotheca pannosa) of nectarines in Israel using strobiluryn and polyoxin B fungicides; mixtures with sulfur, and early bloom applications. Crop Protection 20 (8): 663-668. 